\title{
AS OFICINAS DE INTEGRAÇÃO COMO PRÁTICA PEDAGÓGICA EM TEMPOS DE INCERTEZA E CRISE
}

\author{
Iuri Kieslarck Spacek \\ Vitor Gomes da Silva \\ Roberta Pasqualli
}

Resumo

A forma de organização curricular escolar vem, historicamente, produzindo a fragmentação do conhecimento sobre os objetos. Nesse sentido, as perspectivas de educação que se pautam em currículos integrados tem se demonstrado espaços privilegiados para o estudo e análise dos objetos enquanto síntese de múltiplas determinações, tornando-se alternativas pedagógicas em tempos de incerteza e crise. Sendo assim, este artigo tem como objetivo discutir as concepção de integração curricular apresentadas pelos estudantes de um Curso de Ensino Técnico em Informática Integrado ao Ensino Médio (CTIIEM) a partir da materialização da prática pedagógica na unidade curricular (UC) de Oficina de Integração (OI). A OI compõe um núcleo comum de UC com carga horária específica de preparação, aplicação, síntese e avaliação coletiva do processo pedagógico. Metodologicamente, trata-se de uma pesquisa exploratória e descritiva, de abordagem qualitativa e dialética, caracterizada como caso de estudo. Foi realizada por meio de pesquisa documental, teórica e análise de dados empíricos coletados com 120 estudantes. Como resultados, destacamse duas categorias de análise: (a) a integração curricular como análise de um tema a partir de conhecimentos científicos distintos e, (b) a integração a partir de processos metodológicos diversificados colocando o estudante como sujeito do processo. Como resultados da pesquisa, considera-se que as duas categorias se conectam e expressam movimentos simultâneos de assimilação ativa dos conhecimentos por meio das Oficinas de Integração (OIs) já que, para os estudantes, as propostas tradicionais de ensino parecem como algo totalmente apartado de sua vida, algo com o qual ele não se identifica.

Palavras-chave: ensino; politecnia; currículo integrado; oficinas de integração.

\section{THE INTEGRATION WORKSHOPS AS PEDAGOGICAL PRACTICE IN TIMES OF UNCERTAINTY AND CRISIS}

\begin{abstract}
The form of school curricular organization has historically produced the fragmentation of knowledge about objects. In this sense, the educational perspectives that are based on integrated curricula have proven to be privileged spaces for the study and analysis of objects as a synthesis of multiple determinations, becoming pedagogical alternatives in times of uncertainty and crisis. Therefore, this article aims to discuss the curricular integration conceptions presented by students of a Technical Teaching Course in Informatics Integrated to High School (CTIIEM) from the materialization of pedagogical practice in the curricular unit (UC) of Integration Workshop (OI). The OI comprises a common core of UC with specific hours of preparation, application, synthesis and collective evaluation of the pedagogical process. Methodologically, it is an exploratory and descriptive research, with a qualitative and dialectical approach, characterized as a case study. It was carried out through documentary, theoretical research and analysis of empirical data collected with 120 students. As a result, two categories of analysis stand out: (a) curricular integration as an analysis of a theme based on different scientific knowledge and, (b) integration based on diversified methodological processes, placing the student as the subject of the process. As a result of the research, it is considered that the two categories are connected and express simultaneous movements of active assimilation of knowledge
\end{abstract}


through Integration Workshops (OIs) since, for students, the traditional teaching proposals seem like something totally separated from his life, something he doesn't identify with.

Keywords: teaching; polytechnic; integrated curriculum; integration workshops.

\section{OS TALLERES DE INTEGRACIÓN COMO PRÁCTICA PEDAGÓGICA EN TIEMPOS DE INCERTIDUMBRE Y CRISIS}

Resumen

La forma de organización curricular escolar ha producido históricamente la fragmentación del conocimiento sobre los objetos. En este sentido, las perspectivas educativas que se sustentan en currículos integrados han demostrado ser espacios privilegiados para el estudio y análisis de objetos como síntesis de múltiples determinaciones, convirtiéndose en alternativas pedagógicas en tiempos de incertidumbre y crisis. Por tanto, este artículo tiene como objetivo discutir las concepciones de integración curricular que presentan los alumnos de un Curso de Docencia Técnica en Informática Integrada al Bachillerato (CTIIEM) a partir de la materialización de la práctica pedagógica en la unidad curricular (UC) del Taller de Integración (OI). OI comprende un núcleo común de UC con horas específicas de preparación, aplicación, síntesis y evaluación colectiva del proceso pedagógico. Metodológicamente, es una investigación exploratoria y descriptiva, con enfoque cualitativo y dialéctico, caracterizada como un estudio de caso. Se llevó a cabo mediante investigación documental, teórica y análisis de datos empíricos recolectados con 120 estudiantes. Como resultado, se destacan dos categorías de análisis: (a) la integración curricular como análisis de un tema a partir de conocimientos científicos diferentes y, (b) la integración a partir de procesos metodológicos diversificados, colocando al estudiante como sujeto del proceso. Como resultado de la investigación, se considera que las dos categorías están conectadas y expresan movimientos simultáneos de asimilación activa de conocimiento a través de Talleres de Integración (OIs) ya que, para los estudiantes, las propuestas de enseñanza tradicional parecen algo totalmente separado de su vida, algo con lo que no se identifica.

Palabras clave: docencia; politécnica; plan de estudios integrado; talleres de integración.

\section{CONSIDERAÇÕES INICIAIS}

O processo de escrita desse texto foi mediado pela preocupação que une seus autores, ou sejam, a defesa de uma formação integral forjada no cotidiano escolar, que possua materialidade e aponte para a superação do ensino compartimentado, excessivamente abstrato e descolado da realidade. Nesta direção, as Oficinas de Integração (OIs) do Instituto Federal de Educação, Ciência e Tecnologia de Santa Catarina (IFSC) do Câmpus Chapecó, unidades curriculares que motivaram a pesquisa ora apresentada, são elementos de valorização da construção coletiva, ou seja, materializam a participação qualificada de docentes e estudantes na apropriação do conhecimento.

De acordo com Pasqualli, Silva e Silva (2019a),

Um dos grandes desafios do ensino médio integrado é certa perspectiva reducionista do próprio significado do conceito de integrado, ou seja, pensa-se que a tarefa do docente da área técnica e do docente da formação básica são distintas e nunca se encontram. Ora, em qualquer mero esboço de discussão sobre a formação dos estudantes do ensino médio integrado subjaz a questão do fim de uma formação dualista e o estabelecimento de uma formação que podemos chamar de relacional. (PASQUALLI; SILVA; SILVA, 2019a, p. 513). 
De forma a romper com o apresentado por Pasqualli, Silva e Silva (2019a), o Projeto Pedagógico (PPC) do CTIIEM do IFSC Chapecó destaca que as:

[...] Oficinas de Integração são espaços privilegiados para que educandos e educadores construam conjuntamente as diferentes conexões entre os saberes das áreas do conhecimento. É parte indissociável de cada área do conhecimento, não devendo, portanto, ser considerada como uma disciplina ou unidade curricular isolada e, tampouco, de responsabilidade de um único educador ou grupo de educadores. É, ao contrário, de responsabilidade de todos os educadores envolvidos no curso. (IFSC, 2017, p. 15).

As OIs são unidades curriculares oferecidas ao longo dos quatro anos do curso e divididas, anualmente, em núcleos temáticos, sendo eles: (1) Cultura, Ciência e Sociedade; (2) Trabalho, Tecnologia e Poder; (3) Meio Ambiente e Sustentabilidade e, (4) Informática, Ética e Cidadania. Cabe destacar que cada OI é ministrada por, em média, 5 professores das áreas propedêutica e técnica. A metodologia de trabalho destas unidades curriculares opera em um registro relativamente livre e dialógico já que, além de realizarem planejamento prévio e coletivo, os professores das OIs realizam reuniões periódicas para avaliar o andamento da unidade curricular e traçar os próximos passos a serem dados.

No planejamento prévio, os professores objetivam o levantamento de temas para serem trabalhados a partir do núcleo temático semestral e, quando estes temas estão mais amadurecidos, as propostas são apresentadas aos estudantes para avaliação e diálogo conjunto. Os estudantes podem, evidentemente, apresentar contrapropostas e interesses para que o processo seja definido sempre com base na decisão e planejamento coletivo. A organização desta unidade curricular pode ser vista mais detidamente abaixo:

\begin{abstract}
As Oficinas de Integração acontecerão uma vez por semana em dias e horários definidos pelo grupo de educadores. Delas participarão pelo menos um educador de cada área do conhecimento, de forma rotativa, privilegiando as diferentes unidades curriculares. As oficinas serão coordenadas de forma intercalada por, no mínimo, um professor da formação geral e um professor da área técnica. Caberá a estes professores coordenar as atividades definidas em conjunto por todos os professores, garantindo a articulação entre as diversas etapas desenvolvidas e a execução do cronograma pré-definido. (IFSC, 2017, p. 15)
\end{abstract}

Dessa forma, as OIs buscam promover a autonomia e o pensamento crítico dos estudantes, uma vez que estes têm maior liberdade para escolher, a partir do núcleo temático anual, o conteúdo que será abordado no semestre letivo. Cabe destacar que, por meio da mediação dos professores, não se perde de vista o rigor científico, fundamental ao processo de ensino-aprendizagem em espaços escolares. Além disto, a unidade curricular de OI estimula o trabalho docente coletivo e contribui para a redução da transmissão de conhecimentos de forma estanque e mecânica. Cria espaços para discussão de temas extracurriculares que vão além dos tradicionais conteúdos dados em sala de aula e possuem impacto muitas vezes imediato na vida dos estudantes.

Para Pasqualli, Silva e Silva (2019b, p. 107), projetado a partir de uma perspectiva politécnica, o currículo integrado do IFSC Câmpus Chapecó "tem como referência autores vinculados à pedagogia histórico-crítica, ao materialismo histórico-dialético e a um campo que se constituiu no meio acadêmico como Trabalho e Educação" e, portanto, a OI surge como um alternativa em direção à formação por meio de um currículo que objetive uma formação que considere o ser humano em suas múltiplas dimensões, ou seja, que vá além da formação de um 
DOI: $10.12957 /$ teias. $\%$ Y.55407

técnico habilidoso ou seja, uma formação que considere os múltiplos movimentos do mundo do trabalho.

\begin{abstract}
Para melhor ilustrar a intenção posta nas OIs do IFSC Chapecó destaca-se que a proposta tece uma:

[...] crítica a uma educação meramente instrumental, focada unicamente no mercado de trabalho, a compreensão da técnica e dos conhecimentos técnicos como produção humana, a indissociabilidade e a quebra de hierarquias entre conhecimentos técnicos e gerais, a visão de que o trabalho deve ser um princípio educativo e de que a interdisciplinaridade deve ser um pressuposto que orienta a elaboração dos currículos. (PASQUALLI; SILVA; SILVA (2019b, p. 107).
\end{abstract}

Nesse sentido, este artigo tem como objetivo discutir as concepção de integração curricular apresentadas pelos estudantes do CTIIEM a partir da materialização da prática pedagógica na unidade curricular de OI de modo a trazer à luz quais as concepção de integração curricular que os estudantes apresentam/desenvolvem/constroem a partir desta unidade curricular.

$\mathrm{Na}$ sequência, apresentam-se algumas considerações conceituais fundamentais para a compreensão da temática em tela.

\title{
CONSIDERAÇÕES CONCEITUAIS
}

Para dar forma aos propósitos desta pesquisa, tem-se como tarefa inicial apresentar alguns conceitos que se interpelam constantemente na história do pensamento pedagógico brasileiro. Abordar definições, mesmo que provisórias, de educação integral, trabalho como princípio educativo, politecnia, totalidade, ensino integrado, entre outros, não é tarefa das mais simples, especialmente pelo alto grau de síntese necessário à um artigo científico. Aqui, portanto, lança-se mão de mais uma tentativa de compreender as vicissitudes da concepção de educação concebida de forma integral e integrada. Faz-se necessário, em um primeiro momento, buscarmos as raízes históricas do conceito de educação integral e de politecnia para nos aproximarmos da noção de currículo integrado para aí sim, esboçarmos a proposta das OIs.

Muitas vezes conectada originariamente ao pensamento marxista, a concepção de educação integral encontra seu nascedouro, efetivamente, no pensamento libertário de meados do século XIX, mais propriamente com Pierre-Joseph Proudhon (1809-1865). Proudhon considerava que a educação integral era o suporte de uma educação libertária e, neste sentido, os libertários criticavam a escola tradicional desmascarando o seu caráter ideológico, a qual acreditavam que muitas vezes emergia de forma dissimulada. Por sua vez, as escolas tradicionais visavam a manutenção do status quo e não a superação da estrutura de dominação presente na sociedade daquele período, que rumava a passos largos para o capitalismo e para a fase mais aguda da divisão social do trabalho. Os anarquistas eram claros ao defender que não há escola sem a dimensão política e que uma nova educação deve despertar nos indivíduos a consciência da mudança, da transformação social em prol da justiça e da liberdade (GALLO, 2015, p. 23).

Em Proudhon se encontra a primeira sistematização da compreensão de educação integral, isto é, uma educação que contempla todas as especificidades do indivíduo, que possa preparar para o mundo da cultura e da vida, que inclui o trabalho. No entanto, o trabalho no qual é necessário preparar não é o trabalho alienado em que, segundo Marx (2004), o trabalhador não domina o objeto que produz, mas o trabalho consciente, ontocriativo, livre. É, portanto, a totalidade da vida que emerge na educação integral, que deve ser completa e, sobretudo, enfatizar o trabalho enquanto especificidade libertadora da humanidade. 
[...] é necessário que a educação não se restrinja às ciências, às letras a às artes, de modo geral, isto é, a educação não deve estar voltada apenas para o intelecto, mas deve também dirigir-se para os sentidos e a manipulação das coisas, e o aprendizado artesanal do trabalho. Para a realização da aprendizagem politécnica, não basta uma escola comum, é necessária uma oficina escola, onde a manipulação das coisas seja possível, onde a aplicação prática dos conhecimentos teóricos seja imediata e onde do próprio trabalho prático se possa chegar à formulação e ao entendimento de novos conceitos teóricos (GALLO, 2015, p. 58).

O trabalho pode ser considerado como a atividade definidora e constituidora da existência humana ou, como diria Lukács (2018), é a categoria fundante do ser social. Se consideramos o trabalho a partir desse ponto de vista, é imprescindível que ele ocupe posição central também nos processos educativos. A partir dessa linha argumentativa é que pensa-se no trabalho como princípio educativo central de uma educação integral: das propostas de sua realização por meio do Ensino Integrado e, aqui afirmamos, das OIs.

Para Dore (2014, p. 312), o trabalho como princípio educativo tem suas origens históricas conectadas ao pensamento marxista como "[...] expressão pedagógica da reflexão de Marx sobre o trabalho", visto que a relação entre Marx e a educação encontra voz na tradição do pensamento marxista mais do que na obra marxiana. Porém, o que a obra marxiana dispõe sobre a temática educacional deixou marcas profundas no pensamento educacional brasileiro.

Em 1866, Marx aborda nas 'Instruções para os delegados do conselho geral provisório: as diferentes questões', entre outros assuntos, a questão do trabalho e da educação da juventude trabalhadora, momento este em que emerge, mais claramente, a concepção marxiana de educação:

Por educação entendemos três coisas: Primeiramente: Educação mental. Segundo: Educação física, tal como é dada em escolas de ginástica e pelo exercício militar. Terceiro: Instrução tecnológica, que transmite os princípios gerais de todos os processos de produção e, simultaneamente, inicia a criança e o jovem no uso prático e manejo dos instrumentos elementares de todos os ofícios. (MARX, 1982a, n.p.).

A partir dessa citação se torna possível compreender o entendimento de educação aqui desenvolvida, que alia trabalho, formação cultural e corpo, dirimindo os efeitos danosos da dicotomia entre trabalho manual e trabalho intelectual e configurando o empreendimento politécnico. Posteriormente, Antonio Gramsci, baseado na Escola Humanista, apresentará o trabalho como princípio educativo de maneira mais decisiva, isto é, como "[...] o poder fundamental de pensar e de saber dirigir-se na vida" (GRAMSCI, 1977, p. 1530 apud DORE, 2014, p. 303). Para Gramsci, a função da escola é a preparação dos indivíduos para a vida em sociedade, sociedade esta que tem em seu cerne o trabalho, isto é, a relação dialética em que o homem transforma a natureza e assim se transforma.

Assim, tanto na obra de Marx, como na de Gramsci, as ideias de autonomia, liberdade, totalidade, omnilateralidade ou, como escolhemos apontar, a ideia de politecnia se fazem presentes. É também na abordagem marxista que o conceito de politecnia ganha contornos mais delineados. A politecnia pode ser definida, portanto, como a superação de uma falsa dicotomia entre trabalho manual e trabalho intelectual, mais especificamente no caso das escolas técnicas, a politecnia problematiza o fim da distinção entre conhecimento técnico e núcleo comum. Segundo Saviani (2003, p.138), o conceito de politecnia surge: 
DOI: $10.12957 /$ teias. $\%$ Y.55407

[...] postulando que o processo de trabalho desenvolva, em uma unidade indissolúvel, os aspectos manuais e intelectuais. Um pressuposto dessa concepção é que não existe trabalho manual puro e nem trabalho intelectual puro. Todo trabalho humano envolve a concomitância do exercício dos membros, das mãos, e do exercício mental, intelectual. Isso está na própria origem do entendimento da realidade humana como constituída pelo trabalho. (SAVIANI, 2003, p.138).

A raiz da centralidade do trabalho como princípio educativo é a noção de politecnia. A educação integral deve ser politécnica, ou seja, a politecnia é conditio sine qua non para a efetivação da formação integral. Considera-se, então, que defender o ensino integrado é defender um projeto de formação autônoma, emancipadora e, da mesma forma, entendemos que as OIs funcionam como uma espécie de laboratório para a materialização de um ensino que vise dar conta da totalidade de forma dialética.

A matriz curricular do CTIIEM do IFSC Chapecó é organizada por unidades curriculares, mas isto não significa que o real também se divida da mesma maneira. A realidade nos é dada de forma única, imediata, ou seja, na hora, mas compreende-se que exista a separação por unidade curricular para, de acordo com uma perspectiva mais tradicional de formação, compreendê-la de maneira mais profunda. Entretanto, mesmo que se aceite esta compreensão, o ato de dividir para compreender não deve ser tomado como momento definitivo. Em outras palavras: $\mathrm{O}$ que as UC separam, deve ser trazido à totalidade novamente, isto é, deve se tornar efetivamente realidade, visto que "[...] totalidade não significa todos os fatos. Totalidade significa: realidade como um todo estruturado, dialético, no qual ou do qual um fato qualquer (classes de fatos, conjunto de fatos) pode vir a ser racionalmente compreendido" (KOSIK, 1989, p. 35).

Portanto, é necessário ampliar espaços em que as atividades dos professores da área técnica e dos professores da formação básica se integrem, espaço este, que privilegie o desenvolvimento desta relação, proporcionando condições de objetivação dessa relação. O ensino médio integrado deve ser concebido, de acordo com as palavras de Frigotto (2005, p.76), como:

[...] uma base para o entendimento crítico de como funciona e se constitui a sociedade humana em suas relações sociais e como funciona o mundo da natureza, da qual fazemos parte. Dominar no mais elevado nível de conhecimento estes dois âmbitos é condição prévia para construir sujeitos emancipados, criativos e leitores críticos da realidade onde vivem e com condições de agir sobre ela [...]. (FRIGOTTO, 205, p. 76).

Pretende-se, quiçá, dando um passo atrás, pensar a educação sob uma ótica pouco usual: o trabalho coletivo das OIs. Talvez, não seja muita ousadia para o estudo ora proposto, pensarmos a OI enquanto um caminho para uma nova organização curricular que concretize, fundamentalmente, a função social de um novo currículo, sem gradações, isto é, sem conhecimentos que supostamente aparecem como mais fundamentais que outros. Pensamos que essa hipótese pode ser considerada uma particularidade da tese apresentada por Moura, Filho e Silva (2015) que consideram, a partir da constatação que a materialização de uma escola unitária e politécnica em seu sentido pleno para todos ainda não é uma possibilidade, que o ensino médio integrado é se apresenta como alternativa teórica e ético-política de estabelecimento de uma educação a partir de uma base unitária e de uma concepção de formação integral. Nesse sentido, nosso argumento tem como base o entendimento de que o currículo, 
DOI: $10.12957 /$ teias.\%Y.55407

[...] deve servir para atender às necessidades de alunos e alunas de compreender a sociedade na qual vivem, favorecendo consequentemente o desenvolvimento de diversas aptidões, tanto técnicas como sociais, que os ajudem em sua localização dentro da comunidade como pessoas autônomas, críticas, democráticas e solidárias (SANTOMÉ, 1998, p.187).

Desse modo, a necessidade da materialização de um currículo integrado que ofereça ao aluno a capacidade de desenvolvimento de todas as suas potencialidades, em suma, um currículo que valorize sobretudo a educação em uma perspectiva integral ou politécnica tendo a categoria trabalho como seu fundamento, justifica a investigação das propostas de objetivação desse currículo pelas OIs. pesquisa.

Na sequência, apresenta-se o caminho metodológico trilhado para o desenvolvimento desta

\section{CAMINHO METODOLÓGICO}

Metodologicamente, trata-se de uma pesquisa exploratória e descritiva, de abordagem qualitativa e dialética, caracterizada como caso de estudo. Foi realizada por meio de pesquisa documental, teórica e análise de dados empíricos coletados com 120 estudantes do segundo ao oitavo semestre do CTIIEM do IFSC Câmpus Chapecó. Como instrumento de coleta de dados optou-se por um questionário aplicado aos estudantes via google docs, nos laboratórios de informática da instituição pesquisada no primeiro semestre letivo do ano de 2017.

A escolha pelo questionário teve como critério o amplo número de sujeitos envolvidos na pesquisa e o tempo para a sua realização. Após a elaboração, o questionário passou por um período de validação entre os próprios pesquisadores. O instrumento de coleta foi composto por 14 questões fechadas com a possibilidade de apresentação de justificativa descritiva. Das 14 questões elaboradas, 8 diziam respeito mais diretamente ao problema enunciado.

A análise dos dados foi realizada por meio de análise de conteúdo, mais especificamente, uma análise de conteúdo temática. Conforme Bardin (1979, p. 105) a análise temática consiste em desvendar "os núcleos de sentido que compõem a comunicação e cuja presença, ou frequência de aparição pode significar alguma coisa para o objetivo analítico escolhido".

A análise dos dados foi focada, principalmente, nas justificativas e descrições de respostas às perguntas. No entanto, o caráter geral das respostas foi também um aspecto norteador da análise, apesar de não ser foco da mesma.

Com a posse dos dados realizou-se um movimento de organização, leitura, interpretação, categorização e análise dos dados. A análise, assim como a pesquisa em seu conjunto, teve como fundamentação metodológica o materialismo histórico-dialético. Nesse sentido, o movimento de análise teve como princípio que o objeto do conhecimento só é cognoscível ao ser investigado em suas múltiplas relações, o que por sua vez, implica que é necessária sua compreensão enquanto objeto concreto. De acordo com Marx (1982b, p. 14):

O concreto é concreto porque é síntese de múltiplas determinações, isto é, unidade do diverso. Por isso, o concreto aparece no pensamento como processo da síntese, como resultado, não como ponto de partida, ainda que seja o ponto de partida efetivo e, portanto, o ponto de partida também da intuição e representação. [...] o método que consiste em elevar-se do abstrato ao concreto, não é senão a maneira de proceder do pensamento para se apropriar do concreto, para reproduzi-lo como concreto pensado. (MARX, 1982b, p.14). 
A categorização ocorreu em um processo de constante movimento, partindo do concreto enquanto ponto de partida da intuição e representação (dados imediatos da pesquisa), passando por um processo de análise (organização, categorização e destaque das falas representativas das categorias) que culminou no concreto pensado (categorias representativas do objeto). Nesse movimento foi possível apreender as seguintes categorias analíticas: (a) integração curricular como análise de um tema a partir de conhecimentos científicos distintos e, (b) integração a partir de processos metodológicos diversificados colocando o estudante como sujeito do processo.

Essas categorias não são mutuamente excludentes, mas se inter-relacionam e se complementam, evidenciando particularidades inerentes ao processo aqui analisado. Portanto, são representativas de uma tendência aproximativa do real. São também uma expressão do movimento de inserção do estudante na dinâmica social geral, que requer a integração dos movimentos simultâneos de assimilação ativa dos conhecimentos a partir de um contexto de ensino. (LIBÂNEO, 1984).

Foram considerados os aspectos éticos da pesquisa com seres humanos de acordo com as Resolução vigentes.

\section{ANÁLISES E DISCUSSÕES}

A integração curricular pela abordagem de um tema a partir de conhecimentos científicos distintos

Uma das principais formas de manifestação da integração curricular, segundo constatou-se a partir dos dados coletados pela pesquisa, é realizada por meio da abordagem de uma temática a partir de conhecimentos distintos. Isso pôde ser observado a partir de diversas questões analisadas, com maior expressividade na pergunta relacionada 'à importância de professores de diversas áreas de conhecimento para a integração curricular'. Para este questionamento houve, para quase a totalidade dos estudantes questionados, o reconhecimento da importância e a necessidade para tal unidade curricular. Conforme um dos sujeitos da pesquisa, isso se deve ao fato de que "[...] somente assim iremos ter a real integração entre as matérias, pois apenas um professor não saberia como interagir sobre todas as matérias a não ser a sua própria" (EA $\left.{ }^{1}\right)$ Aqui, também, nos chama a atenção, a percepção que o estudante possui das limitações dos professores em analisar um objeto a partir de outra área de conhecimento que não a de sua formação e/ou atuação. Considera-se que essa 'deficiência' é corrigida na OI a partir do envolvimento de distintos professores, o que já seria uma expressão da integração.

Em outras questões a mesma problemática também emergiu de maneira bastante significativa. Um exemplo está na questão que se refere 'à percepção de integração durantes as aulas', já que a grande maioria dos estudantes afirmam conseguir percebê-la. A integração se explicita na figura dos professores e em suas contribuições, mas não se limita a isso, sendo percebida também na articulação dos conhecimentos, na forma e metodologia de estruturação da oficina além da escolha do tema, conforme se explicita nas falas abaixo:

1 Devido à não vinculação do usuário com a respostas, optou-se por citar as respostas representativas identificandoas por 'E + letras do alfabeto latino' de acordo com a sequência do texto. Desta forma, apesar de termos 120 respostas ao questionário, apenas as definidas como significativas iniciaram a contagem alfabética. 
Todos os professores presentes na oficina demonstram seus conhecimentos em determinado assunto relacionado ao eixo da OI facilitando a integração. (EB). O fato de ter mais de um professor traz o conteúdo trabalhado ter mais conexão com o real, pois se há mais de um meio de se abordar um conteúdo, isso faz com que o assunto fique mais próximo da realidade. (EC).

Durante o desenvolvimento dos projetos há uma interação entre as disciplinas e entre diversos conhecimentos. (ED).

Pois os temas são casados um grupo complementa o outro e no fim forma um grupo apenas. (EE).

É possível perceber a integração não só das matérias em si, mas também, coisas que normalmente em uma escola regular não aprendemos, coisas do cotidiano, que são boas em um geral não só por conteúdo, mas para a vida. (EF).

Os EB e EC evidenciam o papel da contribuição dos professores na discussão dos assuntos abordados nas OIs. Esse papel é importe quando estamos falando de educação escolar. Para Saviani (1986), o papel do professor se objetiva na instrumentalização dos estudantes de ferramentas específicas das unidades curriculares que os mesmos lecionam. No entanto, a proposta de integração aqui analisada vai em direção a superação da fragmentação do conhecimento uma vez que essas ferramentas são usadas e apropriadas em um contexto em que o objeto está sendo considerado como constituinte de uma totalidade e, este fato é visível nas falas dos ED e EE. Para Ramos (2007) a integração entre conhecimentos sobre um determinado objeto sendo analisado enquanto totalidade é um dos sentidos da integração. De acordo com Kosik (1989), o objeto, estabelecido enquanto totalidade, não deve ser compreendido apenas como a soma das suas partes, o que implicaria que a realidade seria incognoscível uma vez que não é possível se apropriar de todos os aspectos da realidade de forma exata, mas apenas no sentido relativo, aproximativo. Como vimos anteriormente, entender o mundo enquanto totalidade significa entender a realidade de maneira estruturada, dialética e racionalmente compreensível. (KOSIK, 1989). Com o desenvolvimento do ser social e com a superespecialização da ciência, há uma tendência a se entender que o conhecimento é setorial, desassociado.

No entanto, uma análise mais cuidadosa mostra que quanto mais esse processo se aprofunda, mais evidente fica o processo de maior unidade do mundo. Essa unidade, no entanto, é formada por momentos e sistemas que compõem setores da realidade. Assim, diferentemente de procedimentos de conhecimento de natureza sistemático-aditivo no qual a compreensão de determinado fenômeno é resultado da soma de conhecimento acerca dos fatos que o compõem em unidades distintas, a compreensão dialética da totalidade parte do significado de que cada momento, cada unidade, é um momento do todo e que o seu conhecimento se processa "em um movimento em espiral, do qual cada início é abstrato e relativo.” (KOSIK, 1989, p. 41).

A concepção na qual o objeto é a soma das suas partes, entendimento pautado no positivismo e no mecanicismo, tem reflexo na construção e estruturação dos currículos atualmente. A perspectiva de integração é uma tentativa de superação a partir da compreensão que o objeto deve ser estudado em sua totalidade, considerada também sua historicidade. Isso, portanto é fundamental para a superação entre a divisão e superespecialização curricular, uma vez que, um objeto nunca é necessariamente objeto específico de determinada área do conhecimento, mas pode ser objeto de diferentes áreas ao mesmo tempo. Essa característica se evidencia na fala do EC. Esse estudo por distintas áreas do conhecimento faz com que o objeto seja compreendido em processo aproximativo cada vez mais rico que se expressa nas metodologias (EE), na delimitação do objeto e na abordagem dos conteúdos. 
Assim, as OIs ão organizadas a partir de uma visão dialética, partindo do princípio de totalidade. De acordo com este princípio, um tema determinado é estudado a partir de um processo de conhecimento que parte de um objeto concreto e, por meio de análises abstratas dos componentes realizadas por processos de análise metodologicamente diversos, sintetiza-se um objeto concreto, agora em outro patamar, enquanto "concreto pensado". (MARX, 1982b, p.14) No meio desse processo há sínteses parciais que são realizadas por distintas metodologias.

As OIs, se mostram para o estudante como momento privilegiado de organização e síntese de distintos conhecimentos, atitudes, comportamentos e atividades apropriadas nas demais unidades curriculares específicas, sejam elas do núcleo básico ou do núcleo técnico. Nesse sentido, o conhecimento, centrado em um tema específico caminha em um movimento espiralado onde o estudante se apropria de conhecimentos sobre um dado objeto por meio de perspectivas diferentes, analisando o objeto a partir de suas múltiplas determinações, ou seja, a partir de distintos aspectos e olhares científicos que são sintetizados em um trabalho final conforme apontaram os estudantes. A OI "[...] integra diferentes matérias e professores, fazendo com que o conhecimento de cada uma se complemente." (EG). Além disso a metodologia de pesquisa, na qual diferentes grupos analisam um dos aspectos do objeto e em seguida os relacionam entre si, que surge na fala do (EE), é expressão desse processo.

No que se refere às temáticas, percebemos que os sujeitos da pesquisa possuem a visão de que a OI é um momento propício para o estudo de temas diversificados, fazendo com que "[...] as aulas nunca sejam umas iguais às outras" $(\mathrm{EH})$. Além disso, uma grande parte dos estudantes a percebem como uma unidade curricular que faz parte de uma aula 'extra classe' (EI). Esse, nos parece, um dos motivos que fazem os estudantes considerarem as OIs como distinta das demais. É importante ressaltar esse aspecto, pois ela aparece intrínseca em algumas colocações dos estudantes e explicitamente em outras, conforme é possível perceber nas respostas às questões relativas à existência de integração nas oficinas:

É possível perceber a integração não só das matérias em si, mas também, coisas
que normalmente em uma escola regular não aprendemos, coisas do cotidiano,
que são boas em um geral não só por conteúdo, mas para a vida. (EJ).
A OI é uma disciplina na qual é feita uma conexão entre o que se aprende na
escola e a vida real. (EK).

Essas falas evidenciam a percepção da escola como lugar onde é necessário ritos próprios desvinculados da sua prática social enquanto indivíduo, ou um lugar descolado dessa prática. Isso evidenciaria como a escola não está cumprindo seu papel uma vez que é entendida como prática artificial, desvinculada da vida real. Conforme Saviani (1986) a educação tem o papel de problematizar a prática social e através da instrumentalização dos sujeitos por meio da aprendizagem de conhecimentos científicos, historicamente formados pela humanidade, alterar a prática social dos estudantes enquanto agentes sociais. Além disso, é possível perceber como o estudante não vê sentido no que estuda. Aquilo que o move a estudar é uma força imposta que não faz parte da sua vida. Isso poderia ser caracterizado como um aspecto da alienação. Conforme Leontiev (2004) psicologicamente, a alienação ocorre como uma cisão entre o que o sujeito faz (significado social de sua ação) e o porquê de ele fazer (sentido). Portanto, ao não compreender que o estudo é uma forma de apropriação da realidade, ou seja, é uma forma de compreender o movimento de constituição da realidade e os limites e possibilidades de atuação do sujeito frente a ela, o estudante estaria em uma atividade alienada, na qual ele se relaciona consigo mesmo, com a objetivação dessa atividade (nova subjetividade), com o objeto de sua atividade (apropriação do objeto em suas múltiplas determinações) e com a sociedade em geral de maneira que essa atividade 
não realiza todas as potencialidades formativas para o indivíduo, como deveria, mas se torna um fardo, algo no qual ele busca estar livre. Parafraseando Marx (2004), o estudante, enquanto estuda na escola, não se afirma, mas nega-se, não se sente bem, mas infeliz. Só se sente junto a si, fora da escola e fora de si na escola.

Deste modo, as falas dos estudantes nos mostram o 'fracasso' da escola em cumprir seu papel de formação dos indivíduos na perspectiva da atuação transformadora e consciente de sua prática social, mas ao mesmo tempo mostram que a experiências das OI tem se apresentado como um momento privilegiado de formação do sujeito na perspectiva de compreensão da realidade e dos objetos em sua totalidade e como agentes transformadores da sua prática, ou seja, ao ensinar 'coisas do cotidiano que são importantes para a vida'. Assim, os estudantes consideram a OI "[...] mais dinâmica [...] ligada à experiência de vida externa." (EL). Isso, torna a OI diferente das demais para os estudantes.

Ao mesmo tempo, grande parte dos entrevistados apontam que as OIs possuem também aspectos iguais aos outras unidades curriculares e os motivos se vinculam mais à forma/metodologias de condução e principalmente de avaliação adotadas pelos professores, pois mesmo tendo "[...] uma proposta diferente das outras matérias, [...] ainda está muito presa aos moldes antigos de ensino". (EM). Nesse mesmo sentido, o EN aponta que "[...] apesar de ser uma matéria na qual estudamos assuntos completamente diferentes do que estamos acostumados, a aula ainda se torna maçante devido o método de conduzir a aula".

Pode-se perceber que a OI aparece para os estudantes como uma UC que promove a integração por intermédio da atuação de diferentes professores, ao abordar diferentes 'assuntos' onde 'cada professor contribui com os conhecimentos de sua área'. Portanto, podemos perceber um movimento que busca abordar um determinado objeto concreto a partir de múltiplos aspectos em uma perspectiva que compreende o objeto enquanto totalidade concreta. Ao mesmo tempo, as metodologias mostram um aspecto que torna possível a apropriação do objeto em suas determinações. No entanto, ainda que sejam poucos os relatos nesse sentido, é importante considerar que a metodologia/forma ao serem similares às utilizadas nas demais unidades curriculares podem tornar as OIs 'maçantes' para o estudante. Esses aspectos metodológicos, mas que também estão ligados ao conteúdo, nos levam à segunda categoria de análise.

Integração a partir de processos metodológicos diversificados colocando o estudante como sujeito do processo

A primeira categoria evidencia o papel dos professores na elaboração e condução do processo de aprendizagem. A presença e participação de professores de diferentes áreas torna manifesta, para o estudante, a integração. No entanto, é impossível nos referirmos a uma perspectiva de formação integral sem nos referirmos à participação do estudante no desenvolvimento da proposta, ou seja, ao papel ativo do mesmo em sua própria formação. Nesse contexto, emerge a segunda categoria de análise na qual é possível perceber o papel de destaque do estudante por meio dos múltiplos processos metodológicos. Isso se manifestou em distintas partes da análise onde os estudantes citaram que a diversificação das metodologias tornava a OI diferenciada. As metodologias diversificadas, como seminários, viagens de estudos, pesquisa de campo, pesquisa teórica, entre outras é, para uma boa parte dos estudantes, o que distingue a unidade curricular das demais. Dentre essas categorias, os estudantes destacam as viagens de estudos como um elemento que pode gerar interesse aos estudantes, conforme podemos notar nas falas abaixo: 
As visitas técnicas são uma maneira diferente de aprender e que aumentam o interesse do aluno pelo assunto, já que é uma atividade mais prática. (EO).

As visitas são a parte mais importante das oficinas, quando saímos do ambiente escola e partimos para um conhecimento maior que é o mundo ali fora, com diversas experiências. (ES).

Podemos inferir que a valorização das visitas de estudo está estreitamente ligada com aquele aspecto que já mencionamos, segundo o qual o estudante percebe a escola enquanto apartada da sua vida, como algo que não lhe será útil. Contraposto a isso, as visitas técnicas possibilitam que os estudantes consigam partir para a sua verdadeira 'vida que é o mundo ali fora'. Esse é um ponto importante, pois que demonstra a necessidade da organização do ensino de modo a fazer sentido para o estudante. Esse, por sua vez, não surge, em relação direta ao conteúdo ensinado, ao privilegiar as 'atividades mais práticas'. Se ocorresse desse modo, estaríamos privilegiando o utilitarismo e o praticismo, ou seja, a "prática sem teoria, ou com um mínimo dela." (SANCHÉZ VÁZQUEZ, 2007, p. 240). O praticismo não necessariamente conduz à aprendizagem significativa, mas ao seu inverso. Isso se deve ao fato de que, segundo Sanchéz Vázquez (2007), no praticismo, enquanto ponto de vista do senso comum, a prática é considerada como oposição à teoria e quanto menos encharcada de elementos teóricos, mais corresponde a ele.

A metodologia pode privilegiar um aspecto em detrimento de outro. No entanto, a perspectiva aqui defendida de integração parte do critério de que o saber escolar deve ser vivo, ou seja, deve colocar os estudantes em atividade para que sintam necessidade de apropriá-lo. Isso, por sua vez, depende da concepção de estudante que se tem. Conforme Saviani (2008) é necessário, para uma atividade educativa que tenha como norte ultrapassar os limites das relações manifestadas imediatamente nas vivências dos estudantes, entendermos o estudante enquanto indivíduo concreto em oposição ao estudante enquanto indivíduo empírico. O indivíduo concreto é

síntese de inúmeras relações sociais. [...] Ele não se enquadra no modelo descrito pela psicologia, pois o indivíduo empírico é uma abstração, pressupõe um corte onde se definem determinadas variáveis que são objetos de estudo. [...] $\mathrm{O}$ aluno empírico, o indivíduo imediatamente observável, tem determinadas sensações, desejos e aspirações que correspondem à sua condição empírica imediata. Estes desejos e aspirações não correspondem necessariamente aos seus interesses reais, definidos pelas condições sociais que o situam enquanto indivíduo concreto. (SAVIANI, 2008, p. 96-97).

Portanto, torna-se imprescindível que a escola possibilite aos estudantes uma compreensão de sua prática social global, para além das manifestações fenomênicas. Entretanto, isso não está relacionado a ensinar conceitos de forma estanque e desconectada das necessidades humanas que deram origem aos mesmos. Compreender, portanto, uma possibilidade de que os conhecimentos sejam significativos aos estudantes é colocá-los em movimento de apropriação em uma perspectiva que este esteja no centro do processo, ou seja, uma assimilação ativa. Conforme Libâneo (2013, p. 89) a assimilação ativa é um processo de "apropriação de conhecimentos e habilidades [...] que se desenvolve com os meios intelectuais, motivacionais e atitudinais do próprio aluno, sob a orientação e direção do professor." Assim, um aspecto importante é o da motivação que parte dos 'interesses'.

O 'interesse' é um elemento que pode colocar o estudante em movimento de apropriação do objeto em sua concreticidade, ou seja, pode colocar o estudante em atividade, como sujeito de seu próprio desenvolvimento. Conforme aponta Leontiev (2017, p. 51) expoente da teoria da 
atividade, o "interesse é a direção determinada que têm as funções cognoscitivas para os objetos e fenômenos da realidade." Assim, o interesse possui um papel preparatório, no entanto, nem sempre efetivo. Isso ocorre, pois, o indivíduo pode buscar conhecer o que é necessário para ele, mas no caso de não existirem condições para que esse interesse se converta em motivo para o estudante, ele não tem a força para estar em atividade de estudo. No entanto, é um pré-requisito essencial para uma atividade de estudos e ensino efetiva, conforme apontam os dados da pesquisa. No caso das Ois os dados nos mostram que o interesse surge a partir de diversos aspectos. Um deles, conforme destacado na fala do EO, está ligado às metodologias, como as visitas técnicas.

Outro aspecto se relaciona ao conteúdo e a metodologia. Os relatos abaixo sublinham o fato. Para os estudantes, a OI,

É uma matéria interessante, e proporciona desafios, mas na maioria das vezes é prazeroso, na maioria das vezes... (EQ).

[...] traz temas que muitas das vezes e do agrado de todos. (ER).

Uma disciplina que requer um tempo de estudo como todas as outras mas é algo onde você pode pesquisar algo de [seu próprio] interesse, na maioria das vezes, o que torna uma pesquisa detalhada em algo mais prazeroso se comparada com as outras matérias. (ES).

O formato OI ao possibilitar delimitações e divisões dos temas geradores das pesquisas que são aprofundadas pelos estudantes é um ponto que se converte em interesse pelos estudantes. No entanto, como destaca o EQ, isso nem sempre ocorre. Isso torna evidente que o 'sucesso' ou o 'fracasso' da proposta de integração desenvolvidas nas OIs não é dado a priori pela sua forma, mas depende de diversos fatores como as formas de organização da oficina, a escolha de assuntos de interesse dos estudantes, as abordagens a serem realizadas, entre outros.

Outro aspecto importante das OI é a metodologia de pesquisa. Essa, essencialmente, coloca os estudantes como protagonistas do processo de aprendizagem. Dita metodologia, comum a todas as OI analisadas, é um elemento essencial para os estudantes e é destacada em diversos depoimentos:

Em minha opinião, importante principalmente para o desenvolvimento de pesquisa e oratória. (ET).

Ela nos faz pesquisar a fundo os assuntos propostos em sala. É uma disciplina muito importante. (U).

O ponto mais forte seriam suas pesquisas de campo. (EV).

Ela nos proporciona conhecimentos diferenciados do que as outras matérias como por exemplo: trabalho em grupo, pesquisa teórica e de campo, além de termos maior preparo para fazer um projeto. (EW).

A OI é uma disciplina voltada para pesquisa integra as matérias. (EX).

É necessário que se trabalhe mais para fazer a pesquisa, a qual muitas vezes envolve pesquisa de campo, para compor um trabalho elaborado ao final da disciplina. (EY).

A pesquisa como técnica de ensino, se liga diretamente com os três aspectos necessários à assimilação ativa dos estudantes indicados por Libâneo (2013, p. 89). Se liga aos aspectos intelectuais e motivacionais, pois o assunto pode ser de 'interesse' dos estudantes, o que pode conduzir que surja uma motivo para sua atividade (EQ, ER, ES), e aos aspectos atitudinais, pois ajuda a aprender a trabalhar em grupo (EE, EW), além de exigir dedicação e estudo adicional para compor a pesquisa (ES, EY). 
A partir desses aspectos, consideramos, a partir da concepção dos estudantes, que a OI consegue, na maioria das vezes, conduzir a uma assimilação significativa, seja por seu conteúdo, como por seu método, explícito mais evidente no momento de realização da pesquisa sobre o objeto estudado.

\section{CONSIDERAÇÕES FINAIS}

As OI segundo a pesquisa nos mostra, tem se tornado um espaço privilegiado que busca um ensino pautado na compreensão dos objetos de estudo a partir de suas múltiplas determinações. Esta questão torna-se clara, quando os estudantes percebem a integração que se materializa pela organização curricular que permite a presença de professores das mais distintas áreas do saber, pelo estudo de temas que não são usualmente foco de ensino e por metodologias, com destaque às pesquisas, que colocam o estudante no papel de sujeito do processo de sua própria aprendizagem.

Faz-se necessário também inferir da pesquisa a relação de distanciamento que o estudante percebe entre 'escola e vida'. Em suma, a escola insurge como algo totalmente apartado da vida do estudante, algo com o qual ele não se identifica. Por outro lado, as OI buscam restabelecer esta conexão na medida em que mobilizam os estudantes a desenvolver, muitas das vezes, seus interesses cotidianos como fundamento da sua própria aprendizagem.

Além disso, a pesquisa também nos apresenta a percepção dos estudantes sobre a limitação dos professores em conectar a sua unidade curricular específica com a totalidade, ou seja, com as demais áreas de conhecimento. Essa limitação é uma questão importante, pois de certa maneira, é o que justifica a existência das OI. Nesse sentido, poderíamos nos perguntar se, caso os professores estivessem preparados para realizar a integração entre o conteúdo específico e outros, na análise de um objeto determinado, haveria a necessidade de existir as OI? Ficam em aberto, e seguem como sugestões de trabalhos futuros, algumas questões relativas à contribuição e impacto dos conteúdos, métodos, habilidades e comportamentos apropriados durante as OIs para o desenvolvimento integral do estudante.

\section{REFERÊNCIAS}

BARDIN, Laurence. Análise de Conteúdo. Lisboa: edições 70, 1979.

DORE, Rosemary. Afinal, o que significa o trabalho como princípio educativo em Gramsci? Cad. CEDES, Campinas. 2014. Disponível em: https://www.scielo.br/pdf/ccedes/v34n94/01013262-ccedes-34-94-0297.pdf. Acesso em: 18 out. 2020.

FRIGOTTO, Gaudêncio. Concepções e mudanças no mundo do trabalho e o ensino médio. In: FRIGOTTO, Gaudencio; CIAVATTA, Maria; RAMOS, Marise Nogueira (Org.). Ensino Médio Integrado: Concepção e contradição. São Paulo: Cortez, 2005.

GALLO, Silvio. Pedagogia Libertária: anarquistas, anarquismos e educação. São Paulo: Intermezzo Editoria, 2015.

IFSC, INSTITUTO FEDERAL DE SANTA CATARINA. Projeto do curso técnico de nivel médio integrado em informática. Chapecó: IFSC, 2017.

KOSIK, Karel. Dialética do Concreto. Rio de Janeiro: Paz e Terra, 1989.

LEONTIEV, Alexis Nikolaevich. O Desenvolvimento do Psiquismo. São Paulo: Moraes, 2004. 
LEONTIEV, Alexis Nikolaevich. As necessidades e os motivos da atividade. In: LONGAREZI, Andreia Maturano; PUENTES, Roberto Valdés (Org.). Ensino Desenvolvimental: Antologia: Livro I. Uberlândia: Editora EDUFU, 2017.

LUKÁCS, Georg. Para a ontologia do ser social. volume 14. Maceió: Coletivo Veredas. 2018.

MARX, Karl. Instruções para os delegados do conselho geral provisório: as diferentes questões. Edições Progresso, 1982a. Disponível em http://www.marxists.org/portugues/marx/1866/08/instrucoes.htm. Acesso em: 14 abr. 2020.

MARX, Karl. Para a Crítica da Economia Política. São Paulo: Abril Cultural, 1982b.

MARX, Karl. Manuscritos econômico-filosóficos. São Paulo: Boitempo, 2004.

LIBÂNEO, José Carlos. Democratização da escola pública: a pedagogia crítico-social dos conteúdos. São Paulo: Loyola, 1984.

LIBÂNEO, José Carlos. Didática. São Paulo: Cortez, 2013.

MOURA, Dante Henrique; FILHO, Domingos Leite Lima; SILVA, Mônica Ribeiro. Politecnia e formação integrada: confrontos conceituais, projetos políticos e contradições históricas da educação brasileira. Revista Brasileira de Educação. 2015. Disponível em: https://www.scielo.br/pdf/rbedu/v20n63/1413-2478-rbedu-20-63-1057.pdf. Acesso em: 01 out. 2020.

PASQUALLI, Roberta; SILVA, Angela; SILVA, Vitor Gomes da. A Pesquisa como Princípio Educativo no Currículo Integrado. Debates em Educação, Maceió 2019a. Disponível em: https://www.seer.ufal.br/index.php/debateseducacao/article/view/6294. Acesso em: 18 out. 2020.

PASQUALLI, Roberta; SILVA, Vosnei; SILVA, Adriano Larentes da. Limites e potencialidades de materialização do currículo integrado: uma análise dos planos de ensino e diários de classe. Revista Contexto Educação. 2019b. Disponível em: https://www.revistas.unijui.edu.br/index.php/contextoeducacao/article/view/7631. Acesso em: 18 out. 2020.

RAMOS, Marise Nogueira. Concepção do ensino médio integrado. In: Seminário sobre Ensino Médio. 2008. Disponível em: https://tecnicadmiwj.files.wordpress.com/2008/09/texto-concepcao-doensino-medio-integrado-marise-ramos1.pdf. Acesso em: 21 abr. 2020.

SANTOMÉ, Jurjo Torres. Globalização e Interdisciplinaridade: o currículo integrado. Trad. Cláudia Shiling. Porto Alegre: Artes Médicas Sul, 1998.

SAVIANI, Demerval. Escola e democracia: teorias da educação, curvatura da vara, onze teses sobre educação e política. Campinas: Autores Associados, 1986.

SAVIANI, Demerval. O choque teórico da politecnia. In: Trabalho, Educaşão e Saúde, Rio de Janeiro, FIOCRUZ/EPSJV. 2003.

SAVIANI, Demerval. Pedagogia Histórico-Crítica: Primeiras Aproximações. $10^{\mathrm{a}}$ ed. Revista e ampliada. Campinas: Autores Associados, 2008.

SILVA, Adriano Larentes da; PASQUALLI, Roberta; GREGGIO, Saionara; AGNE, Sandra Aparecida Antonini (Org.). O currículo integrado no cotidiano da sala de aula. Florianópolis: IFSC, 2016. Disponível em: https://www.ifsc.edu.br/documents/30701/523474/o_curriculo_integrado.pdf/6151bc15-d409b17b-1efd-3f21e89314e3. Acesso em: 18 out. 2020. 
DOI: $10.12957 /$ teias. $\%$ Y.55407

SÁNCHEZ VÁZQUEZ, Adolfo. Filosofia da Práxis. Tradução de Maria Encarnación Moya Buenos Aires: Consejo Latinoamericano de Ciências Sociales-CLACSO, 2007.

Submetido em outubro de 2020 Aprovado em marco de 2021

\section{Informações do(a)(s) autor(a)(es)}

Iuri Kieslarck Spacek

Instituto Federal de Santa Catarina - IFSC

E-mail: iuri.spacek@ifsc.edu.br

ORCID: https://orcid.org/0000-0002-8785-9912

Link Lattes: http://lattes.cnpq.br/8231413467135132

Vitor Gomes da Silva

Instituto Federal de Santa Catarina - IFSC

E-mail: vitor.gomes@ifsc.edu.br

ORCID: https://orcid.org/0000-0001-7908-4494

Link Lattes: http://lattes.cnpq.br/6256999639766748

Roberta Pasqualli

Instituto Federal de Santa Catarina - IFSC

E-mail: roberta.pasqualli@ifsc.edu.br

ORCID: https://orcid.org/0000-0001-8293-033X

Link Lattes: http://lattes.cnpq.br/6932842326580345 